\title{
UNUSUAL COMPLICATION IN A CHILD WITH DIABETIC KETOACIDOSIS
}

\author{
Swapna Ponnambalam, Poovazhagi Varadarajan, Seenivasan Subramani, Ramesh Subramanian. \\ Pediatric Intensive Care Unit, Department of Pediatrics, Institute of child health, Egmore, Tamil Nadu, \\ India.
}

\begin{abstract}
Thrombotic microangiopathy in association with diabetic ketoacidosis (DKA) is a rare entity. We describe a two-year-old child presenting with new onset DKA who developed microangiopathic hemolytic anemia, thrombocytopenia, renal failure, fever and altered sensorium during treatment. Thrombotic thrombocytopenic purpura (TTP) was suspected and prompt treatment initiation with fresh frozen plasma halted the ongoing hemolysis. Child however had regression of milestones which he subsequently regained and is being followed up.
\end{abstract}

ARTICLE HISTORY

Received 27 July 2020

Accepted 21 November 2020

\section{KEYWORDS}

Thrombotic microangiopathy, diabetic ketoacidosis

\section{Introduction}

Diabetic ketoacidosis (DKA) in children can rarely be complicated by new onset thrombocytopenia. Sepsis is one of the common causes for thrombocytopenia in children. But identification of children with DKA with thrombotic microangiopathy needs high degree of suspicion as early diagnosis and treatment decreases the mortality and morbidity. Thrombotic thrombocytopenic Purpura (TTP), Hemolytic Uremic syndrome (HUS) and Disseminated Intravascular Coagulation (DIC) can complicate DKA and present with thrombocytopenia2,3,4,5,6,7 TTP with DKA in children is reported only in handful of cases in literature. $3,4,5,6,7$ Children with DKA presenting with thrombocytopenia need prompt evaluation for microangiopathic hemolysis and neurological features. We present a 2-year-old child who presented as new onset DKA with thrombocytopenia, hemolytic anaemia, renal failure, fever, altered sensorium and seizures.

\section{Case Report}

A two-year-old male weighing $12 \mathrm{~kg}$ presented with fever and breathlessness for 3 days. He was diagnosed to have severe DKA in another hospital and referred to our hospital for further management. He had polyuria and polydipsia for two weeks. He presented to our hospital with hypotensive shock and was resuscitated with $30 \mathrm{ml} / \mathrm{kg}$ of normal saline and started on dopamine infusion at $10 \mu \mathrm{g} / \mathrm{kg} / \mathrm{min}$. Fluid therapy was continued as normal saline at $100 \mathrm{ml} / \mathrm{kg}$ with potassium chloride plus maintenance fluid for 48 hours and insulin infusion at $0.1 \mathrm{U} / \mathrm{kg} / \mathrm{hr}^{1}{ }^{1}$ His initial Glasgow Coma Scale (GCS) was E3V3M5. At 4 hours of therapy, he had a fall in GCS to E2V2M4 and cerebral edema was suspected. He was given a stat dose of $3 \%$ saline at $5 \mathrm{ml} / \mathrm{kg}$ and maintained on a continuous infusion of $0.5 \mathrm{ml} / \mathrm{kg} / \mathrm{hr}$ and fluids were restricted to two-thirds of maintenance

Address for Correspondence: Dr. Poovazhagi Varadarajan, Plot no. 19 \& 20, 1st Cross street, Andal Gardens, Ramapuram, Chennai 600 089, India.

Email: poomuthu@gmail.com

(C)2021 Pediatric Oncall requirement. He was also intubated and ventilated with $30^{\circ}$ head end elevation and maintained in neutral position. Euvolemia, normothermia, euglycemia, normal $\mathrm{PaO} 2$ and $\mathrm{PaCO} 2$ were strictly targeted. After 48 hours, his GCS improved to E4V4M6 and hence he was extubated. His $\mathrm{pH}$ improved to 7.36 and bicarbonate to $16 \mathrm{mmol} / \mathrm{l}$ and he was switched over from insulin infusion to subcutaneous dose at 1 unit/ $\mathrm{kg} /$ day. On day 2 of illness, he had declining platelets (platelet count- 95000 cells $/ \mathrm{mm}^{3}$ ) and acute kidney injury (AKI) (p RIFLE-failure) (Table 1). Acute kidney injury was managed with restriction of fluids (urine output plus insensible water losses) and furosemide at $1 \mathrm{mg} / \mathrm{kg} /$ day. His platelets and haemoglobin continued to decline in the subsequent days. On day 5 of hospitalization, he had an episode of seizure and was reintubated in view of low GCS (GCS-6). His blood sugar, serum sodium and calcium were within normal limits (table 1).CT brain was normal. He had fever, pallor, splenomegaly, hemoglobin of $6.8 \mathrm{~g} / \mathrm{dl}$ and a platelet count of $56,000 \mathrm{cells} / \mathrm{mm}^{3}$. Peripheral smear for malarial parasite was negative on two occasions. Other laboratory parameters are shown in table 1 . Peripheral smear revealed microcytic hypochromic anemia with normocytic anemia with schistocytes, pencil cells, tear drop cells and elliptocytes suggestive of microangiopathic hemolytic anemia with thrombocytopenia. Corrected reticulocyte count was $3 \%$. Direct coombs test was negative. Serum LDH was 1647 IU/L (Normal range-120- 300 IU/L). Coagulation profile was normal (Prothrombin time $-16 \mathrm{sec}$, activated partial thromboplastin time - $34 \mathrm{sec}$, INR-0.9). Serum C3 levels were $231 \mathrm{mg} / \mathrm{dl}(80-200 \mathrm{mg} / \mathrm{dl})$ and antifactor $H$ was negative. ADAMTS 13 (A Disintegrin A and Metalloproteinase with Thrombospondin Motifs) levels could not be done due to economic constraints. There was no hematuria/proteinuria and no pus cells in urine and urine culture was sterile. Serum triglyceride was $137 \mathrm{mg} / \mathrm{dl}$ and fibrinogen were $190 \mathrm{mg} / \mathrm{dl}$. HbA1C was $9.34 \%$. He was given a packed red blood cell transfusion of $10 \mathrm{ml} / \mathrm{kg}$ for anemia and was treated with meropenem and fluconazole in view of persistent fever. Presence of fever, anemia, thrombocytopenia, seizures, elevated renal parameters and hemolysis made us 
suspect TTP and he was given fresh frozen plasma transfusions for 5 days. Repeat LDH showed a declining trend and platelet counts improved to $1,60,000 / \mathrm{mm}^{3}$ on day 11 of hospital stay. He was extubated 3 days after reintubation and although he had spontaneous eye-opening, he was not following light and not able to obey commands. On day 11 of hospital stay, he developed abnormal orofacial movements with lip automatisms, tongue thrusting and choreoathetoid movements. Suspecting autoimmune encephalitis, he was given on intravenous immunoglobulin $2 \mathrm{~g} / \mathrm{kg}$ over 5 days. Magnetic Resonance Imaging of the brain with angiogram and venogram revealed bilateral parietofrontal hyperintensities probably post ictal changes. Cerebrospinal fluid (CSF) analysis done on Day 11 was normal. CSF culture was sterile. CSF PCR for herpes simplex virus, enterovirus and IgM for Japanese encephalitis virus were negative. CSF autoimmune panel for antibodies against NMDA, AMPA1, AMPA2, CASPR, LG1 and GABAB were negative. His vision and hearing were normal. He continued to have fever for 12 days. Widal, Macroscopic Slide Agglutination Test for Leptospira (MSAT) , IgM Scrub typhus, IgM dengue and smear for malaria were negative. Blood, urine and endotracheal aspirate showed no growth. GAD antibody levels were $881 \mathrm{U} / \mathrm{ml}$ (>5U/ml- positive). He was started on trihexyphenidyl and haloperidol for persistent involuntary movements.

On discharge, child had improvement in involuntary movements but there was regression of motor and language milestones. At 6 weeks of discharge, child was interacting with mother. At 8 weeks he was able to sit

Table 1. Laboratory parameters

\begin{tabular}{|c|c|c|c|c|c|c|c|c|c|c|}
\hline & Day 1 & Day 2 & Day 3 & Day 5 & $\begin{array}{c}\text { Day } 7 \\
\text { Day } \\
1 \text { of } \\
\text { FFP) }\end{array}$ & Day 8 & Day 9 & $\begin{array}{c}\text { Day } \\
10\end{array}$ & $\begin{array}{c}\text { Day } \\
13\end{array}$ & $\begin{array}{c}\text { Day } \\
15\end{array}$ \\
\hline $\begin{array}{l}\text { Hemoglobin (g/ } \\
\mathrm{dl} \text { ) }\end{array}$ & 8 & 6.3 & 5.1 & 6.8 & 6.2 & 7.2 & 6.9 & 6.9 & 7.0 & 7.3 \\
\hline $\begin{array}{l}\text { Total count } \\
\left(\text { cells } / \mathrm{mm}^{3} \text { ) }\right.\end{array}$ & 19700 & 13400 & 10400 & 10600 & 11800 & 12500 & 13600 & 8900 & 6400 & 12700 \\
\hline $\begin{array}{l}\text { Platelets (cells/ } \\
\mathrm{mm}^{3} \text { ) }\end{array}$ & 450000 & 95000 & 83000 & 56000 & 52000 & 59000 & 85000 & 135000 & 179000 & 350000 \\
\hline Urea (mg/dl) & 22 & 80 & 98 & 65 & 52 & 16 & 16 & 18 & 21 & 19 \\
\hline $\begin{array}{l}\text { Creatinine (mg/ } \\
\mathrm{dl} \text { ) }\end{array}$ & 1 & 1.2 & 0.9 & 1 & 0.8 & 0.4 & 0.3 & 0.3 & 0.4 & 0.2 \\
\hline $\begin{array}{l}\text { Serum Sodium } \\
(\mathrm{mEq} / \mathrm{l})\end{array}$ & 129 & 160 & 163 & 155 & 148 & 153 & 153 & 148 & 142 & 134 \\
\hline $\begin{array}{l}\text { Serum } \\
\text { potassium } \\
(\mathrm{mEq} / \mathrm{I})\end{array}$ & 4 & 2.7 & 4 & 4.5 & 2.8 & 2.9 & 3.1 & 3.1 & 3.3 & 4.1 \\
\hline LDH (IU/I) & & & 1647 & 1133 & & & & 939 & & \\
\hline AST (IU/I) & & & 269 & & & 135 & & & 74 & \\
\hline ALT (IU/I) & & & 574 & & & 416 & & & 33 & \\
\hline $\begin{array}{l}\text { Serum } \\
\text { magnesium (mg/ } \\
\text { dl) }\end{array}$ & & & & 1.2 & 1.8 & 1.6 & 1.2 & 1.7 & 2.2 & \\
\hline $\begin{array}{l}\text { Serum calcium } \\
(\mathrm{mg} / \mathrm{dl})\end{array}$ & & & 9 & 9.2 & 7.4 & 7.7 & 6.8 & & & 9.2 \\
\hline Ferritin (ng/ml) & & & & & & 214 & & & & \\
\hline $\mathrm{pH}$ & 7.02 & 7.14 & 7.36 & 7.4 & 7.37 & 7.47 & 7.46 & & & \\
\hline $\begin{array}{l}\text { Bicarbonate } \\
(\mathrm{mmol} / \mathrm{l})\end{array}$ & 5 & 8.4 & 16 & 18.2 & 18.8 & 19.6 & 22.6 & & & \\
\hline $\begin{array}{l}\text { Random blood } \\
\text { sugar (mg/dl) }\end{array}$ & 450 & 383 & 236 & 154 & 239 & 105 & 239 & 348 & 177 & 164 \\
\hline
\end{tabular}

LDH - lactate dehydrogenase, ALT - Alanine aminotransferase, AST- Aspartate aminotransferase 
with support and talk few words. GAD antibody titres after 3 months were $32 \mathrm{U} / \mathrm{ml}$. Child is being followed up.

\section{Discussion}

Cerebral edema is the commonest complication of DKA with increased morbidity and mortality. ${ }^{1}$ Shock, renal failure, mucormycosis, venous thrombosis are other complications reported in children with DKA1. TAMOF (Thrombocytopenia Associated Multi Organ Failure) is a devastating microangiopathy that can occur rarely with new onset Type 1 Diabetes mellitus. ${ }^{3,4,5,6,7}$ It is defined by the triad of new onset thrombocytopenia (less than 100,000 cells $/ \mathrm{mm}^{3}$ ), multiorgan dysfunction (at least 2 failing organs), and increased lactate dehydrogenase (LDH) and depends on the presence of red cell fragments (schistocytes), diagnostic of thrombotic microangiopathy. ${ }^{3}$ This child had fever, thrombocytopenia, abnormal mental status, seizures, renal dysfunction and hemolytic anemia which is the pentad for TTP. Renal dysfunction was brief and not predominant unlike in HUS. Coagulation profile was normal unlike in DIC. Presence of acute kidney injury is $100 \%$ in HUS, $58 \%$ in TTP and $42 \%$ in DIC. ${ }^{8}$

TTP is a phenotype with microangiopathy due to ADAMTS13 deficiency. ${ }^{8}$ ADAMTS 13 (A Disintegrin A and Metalloproteinase with Thrombospondin motifs) normally cleaves ULvWF (ultra large von Willebrand factor. ULvWF molecules are hyperadhesive and cause spontaneous platelet aggregation. Deficiency of ADAMTS13 can result in accumulation of ULVWF. TTP can be congenital or acquired. Both have low levels of ADAMTS13 $(<10 \%)$. Congenital TTP is due to mutations in ADAMTS13 and acquired is due to inhibitors to ADAMTS139. Children with TAMOF usually have concurrent sepsis10. In our patient ADAMTS13 activity median level was $39 \%$ (not $<10 \%$ as in TTP). Mortality in TTP has reduced from $100 \%$ to $20 \%$ with the use of plasma exchange. ${ }^{10}$ The management strategies for underlying TTP include replenishment of ADAMTS 13, removal of inhibitors and removal of ultra large von Willebrand factor(ULvWF). This is ideally achieved by plasma exchange. Plasma exchange is most effective when initiated within 24 hours of disease onset. ${ }^{9}$ The end point of therapy would be resolution of thrombocytopenia ( $>150,000 /$ cumm) and no further neurological deterioration. Fresh frozen plasma transfusion only replaces ADAMTS 13 . Other modalities of treatment include steroids and Rituximab ${ }^{11}$ (though not FDA approved for acquired TTP). They can remove the IgG autoantibodies to ADAMTS13. Though plasma exchange is the first line therapy, considering its lack of availability in resource limited settings, plasma infusion may represent an alternative. ${ }^{12}$ Outcome is good with prompt fresh frozen plasma transfusions. Newer agents that are currently being evaluated include recombinant ADAMTS $^{13}, \mathrm{~N}$ - acetylcysteine and proteasome inhibitors like Bortezomib. ${ }^{13}$ The regression of acquired skills which is encountered with thrombotic microangiopathy usually recovers over time. ${ }^{3}$

\section{Conclusion}

Thrombocytopenia in children with DKA needs to be identified early to diagnose thrombotic microangiopathies. Pentad of fever, thrombocytopenia, seizures, renal dysfunction and microangiopathic hemolytic anemia point to a diagnosis of TTP. Plasma exchange, fresh frozen plasma and steroids constitute the line of management for TTP.

\section{Compliance with Ethical Standards}

Funding None

Conflict of Interest None

\section{References:}

1. Wolfsdorf JI, Glaser N, Agus M, Fritsch M, Hanas R, Rewers A, et al. ISPAD Clinical Practice Consensus Guidelines 2018: Diabetic ketoacidosis and the hyperglycemic hyperosmolar state. Pediatr Diabetes. 2018;19 Suppl 27:155-177

2. Bilici M, Tavil B, Dogru O, Davutoglu M, Bosnak M. Diabetic ketoasidosis is associated with prothrombotic tendency in children. Pediatr Hematol Oncol. 2011;28:418-424

3. Kumar R, McSharry B, Bradbeer P, Wiltshire E, Jefferies C. Thrombocytopenia-associated multiorgan failure occurring in an infant at the onset of type 1 diabetes successfully treated with fresh frozen plasma. Clin Case Rep. 2016;4:671-674

4. Khan MR, Maheshwari PK, Haque A. Thrombotic microangiopathic syndrome: a novel complication of diabetic ketoacidosis. Indian Pediatr. 2013;50:697-699.

5. Alsaied T, Goldstein SL, Kaddourah A, Poynter SE. Thrombocytopenia-associated multi-organ failure caused by diabetic ketoacidosis. Pediatr Int. 2016;58:232-234

6. Patra KP, Scott LK. Diabetic ketoacidosis preceding thrombocytopenia associated multiple organ failure in a child. JOP. 2011;12:40-43

7. Mostofizadeh N, Arefnia S, Hashemipour M, Dehkordi EH. Thrombotic Thrombocytopenic Purpura in a Child with Diabetic Ketoacidosis. Adv Biomed Res. 2018;7:33

8. Nguyen TC, Cruz MA, Carcillo JA. ThrombocytopeniaAssociated Multiple Organ Failure and Acute Kidney Injury. Crit Care Clin. 2015;31:661-674

9. Nquyen TC, Carcillo JA. Bench-to-bedside review: Thrombocytopenia-associated multiple organ failure -a newly appreciated syndrome in the critically ill. Crit Care. $2006 ; 10: 235$

10. Nguyen TC. Thrombocytopenia-Associated Multiple Organ Failure. Crit Care Clin. 2020;36:379-390

11. Bommer M, Wölfle-Guter M, Bohl S, Kuchenbauer F. The differential diagnosis and treatment of thrombotic microangiopathies. Dtsch Arztebl Int. 2018;115:327-334

12. Coppo P, Bussel A, Charrier S, Adrie C, Galicier L, Boulanger $E$, et al. High-dose plasma infusion versus plasma exchange as early treatment of thrombotic thrombocytopenic purpura/hemolytic-uremic syndrome. Medicine (Baltimore). 2003;82:27-38

13. Blombery $P$, Scully $M$. Management of thrombotic thrombocytopenic purpura: current perspectives. J Blood Med. 2014;5:15-23 